\title{
XXXII. Observations on the preceding memoir
}

\author{
Sir David Brewster K.H. LL.D. F.R.S. V.P.R.S. Ed.
}

To cite this article: Sir David Brewster K.H. LL.D. F.R.S. V.P.R.S. Ed. (1832) XXXII. Observations on the preceding memoir, Philosophical Magazine Series 3, 1:2, 146-147, DOI:

10.1080/14786443208647854

To link to this article: http://dx.doi.org/10.1080/14786443208647854

$$
\text { 曲 Published online: } 01 \text { Jun } 2009 .
$$

Submit your article to this journal $\pi$

\section{Article views: 1}

Q View related articles ¿ 


\section{Sir D. Brewster's Observations on M. Rudberg's Memoir.}

We thus obtain 0.99560. My experiments give $\frac{n^{\prime \prime}}{n^{\prime}}=0.99542$,

which is 0.00018 in defect. 'These differences, however, evidently arise, on the one hand, from the difficulty of determining these ratios by experiments on refraction with prisms differently cut, with a precision comparable to that which we obtain by means of experiments on diffraction; and on the other hand from the probable inaccuracy in the value of the inclination of the optical axes found by the observation of the coloured rings.

XXXII. Observations on the preceding Memoir. By Sin David BreWster, K.H. LL.D. F.R.S. V.P.R.S. Ed.

NOTWITHSTANDING the great accuracy and value of the preceding observations, and the importance of the deductions which the author has drawn from them, yet we are constrained to state, that almost all the general principles at which M. Rudberg has arrived have been previously established by English philosophers, though not by observations made by means of the fixed lines in the spectrum.

The variation of the inclination of the optic axes with the different colours of the spectrum, and the increase of that angle with the refrangibility of the colour in some crystals, such as Arragonite, and its decrease with the refrangibility in other crystals, such as topaz, is the discovery of Sir John F. W. Herschel, and one of the most important that has been made on the subject of double refraction; and yet the name of Sir John Herschel is not once mentioned. Sir John indeed did not examine Arragonite and topaz, but he found the very same phænomena in sulphate of barytes and Rochelle salts; and as I had myself discovered that all those crystals in which the inclination of the optic axes increases with the refrangibility, have the red ends of their systems of rings inwards, or towards the axis $A$; while those in which this inclination decreases with the refrangibility have the red ends of their rings outwards, or towards the axis B, and had determined that Arragonite had the red ends of its rings inwards, and topaz the red ends outwards*; the variation of the inclination of the optic axes in these two minerals, and its inverse character, were both known before M. Rudberg's experiments. 'To M. Rudberg, however, there remains the merit of having given the values of these angles, and that too in reference to fixed points of the spectrum.

It is impossible to overlook the great difference between theory and observation in the inclination of the optic axes of Arragonite and topaz as given by M. Rudberg. His observa-

Art, Optics, in the Edinburgh Eneyclopadia, vol. xv. p. 596. 
tions make the apparent inclination in Arragonite a little more than $32^{\circ}$, whereas the theory makes it fully $34^{\circ}$. According to my observations, the apparent inclination was $31^{\circ} 15^{\prime}$, and the real inclination $18^{\circ} 18^{\prime}$, computed with an index of 1.693 . Upon re-examining this crystallized plate some years afterwards, I found that its surface was inclined to the axis $\mathbf{A}$; and upon measuring the inclination, I found that the true inclination of the optic axes was $17^{\circ} 33^{\prime}$, which corresponds to an apparent inclination of about $29^{\circ} 56^{\prime}$ for the mean ray of the spectrum. Different crystals, however, have different inclinations; so that we are not entitled to compare this result with that which is deduced from theory.

The discrepancy between theory and observation is still greater in topaz, amounting to $8^{\circ}$ in the inclination of the optic axes, if the specimen used by $M$. Rudberg had the same structure as that which was used by $M$. Biot and myself. Taking the index of topaz at 1.636 , I found the apparent inclination of the axes to be $121^{\circ} 16^{\prime}$, and the real inclination $64^{\circ} 22^{\prime}$, which, from the excellence of the specimen which I used, cannot, I think, err above half a degree. M. Rudberg will no doubt measure the inclination of the axes in every specimen by which he has obtained the theoretical inclination.

In expressing a hope that $M$. Rudberg may continue his valuable observations, with other crystallized bodies, we trust he will excuse us for adding, that though the subject of double refraction is under the deepest obligation to M. Fresnel, yet other philosophers have wrought in the same field before him; and that his transcendent merits would not be diminished by a proper recognition and acknowledgement of their antecedent labours.

XXX1II. Notes on the History of English Geology. By William Henry Fitton, M.D. F.R.S. \& c.

\section{To the Editors of the Philosophical Magazine and. Journal.} Gentlemen,

\footnotetext{
$A \mathrm{~N}$ article which I published in the Edinburgh Review for A February 1818, On the Geological Map, and other works of Mr. William Smith*, having been frequently referred to, the historical part of it was printed, with some additions, in

† The following is a list of Mr. Smith's works, prefixed to the article in the Review,-vol. xxix. p. 310, \&c.

"1. A Delineation (Map) of the Strata of England and Wales, with Part of Scotland; exhibiting the Collieries and Mines, the Marshes and Fenlands originally overflowed by the Sea, and the Varieties of Soil accord$\mathrm{U} 2$
} 